Journal of Vocational Health Studies

www.e-journal.unair.ac.id/index.php/JVHS

\section{ANALYSIS EXPOSURE INDEX AS AN OPTIMIZATION EFFORT ON EXAMINATION CHEST POSTERIOR ANTERIOR}

\author{
ANALISA EXPOSURE INDEX SEBAGAI UPAYA OPTIMISASI PADA \\ PEMERIKSAAN CHEST POSTERIOR ANTERIOR
}

Muhammad Irsal 1,2, Firdha Adlia Syuhada ${ }^{3,4}$, Yolanda Pangestu Ananda ${ }^{4}$, Andre Galih Pratama Putra ${ }^{4}$, Muhammad Rizky Syahputera ${ }^{4}$, Syahputera Wibowo ${ }^{4}$, Rizky Kahar ${ }^{4}$

${ }^{\prime}$ Medical Physicist, Emergency Hospital for COVID - 19 Wisma Atlet Jakarta. Jakarta - Indonesia

${ }^{2}$ Department of Radiodiagnostic and Radiotherapy, Health Polytechnic Ministry of Health Jakarta II. Jakarta-Indonesia

${ }^{3}$ Postgraduate Diagnostic Imaging Program, Health Polytechnic of Semarang. Semarang - Indonesia.

${ }^{4}$ Radiographers, Emergency Hospital for COVID - 19 Wisma Atlet Jakarta. Jakarta - Indonesia

\section{A B S T R A C T}

Background: Radiographers are responsible for producing image quality which can provide accurate diagnostic information by considering the lowest possible radiation dose according to the As Low As Reasonably Achievable (ALARA) principle. Participation between radiographers and medical physicists is needed in optimizing efforts to control the selection of exposure factors by the required clinical radiographic examination. Purpose: To analyze exposure index on examination chest posterior-anterior. Methods: Quantitative descriptive by analyzing the percentage of exposure index results used in chest PA radiographs as an effort to optimize: image quality and radiation dose indicators on chest $P A$ examinations. Results: Optimization of exposure percentage results of $68 \%, 25 \%$ underexposure, $4 \%$ underexposure, $2 \%$ overexposure, $1 \%$ overexposure (noise). Radiographers have tried to optimize: image quality and image radiation dose by selecting exposure factors that are tailored to the patient's condition and maximizing post-processing for increased quality. Conclusion: In optimizing the CR imaging system, it is necessary to understand exsposure index, this is related to the underexposed, optimal, and overexposed categories, besides radiographers can take advantage of post processing to improve image quality.

\section{A B S T R A K}

Latar belakang: Radiografer bertanggung jawab dalam menghasilkan kualitas citra yang mana mampu memberikan informasi diagnosa secara akurat dengan mempertimbangkan pemberian dosis radiasi serendah mungkin sesuai prinsip As Low As Reasonably Achievable (ALARA). Dibutuhkan peran serta antara radiografer dan fisikawan medik dalam melakukan upaya optimisasi untuk mengendalikan pemilihan faktor eksposi sesuai dengan klinis pemeriksaan radiografi yang dibutuhkan. Tujuan: Untuk menganalisis indeks paparan pada pemeriksaan dada bagian anterior posterior. Metode: Bersifat deskriptif kuantitatif dengan melakukan analisa persentase hasil exposure index yang digunakan pada pemeriksaan radiografi chest PA sebagai upaya optimisasi: kualitas citra dan indikator dosis radiasi pada pemeriksaan chest PA. Hasil: Hasil persentase optimization of exposure sebesar $68 \%$, underexposure $25 \%$, underexposure (noise) $4 \%$, overexposure $2 \%$, overexposure (noise) $1 \%$. Radiografer telah mengupayakan optimisasi: kualitas citra dan dosis radiasi citra dengan pemilihan faktor eksposi yang disesuaikan dengan kondisi pasien dan memaksimalkan post processing untuk meningkat kualitas. Kesimpulan: Dalam melakukan upaya optimisasi pada sistem pencitraan CR perlu pemahaman tentang El, hal ini berkaitan tentang kategori underexposed, optimal dan overexposed, selain itu radiografer dapat memanfaatkan post

\section{Research Report}

Penelitian

\section{ARTICLE INFO}

Received 28 July 2020 Accepted 9 September 2020 Online 19 November 2020

*Korespondensi (Correspondence): Muhammad Irsal

E-mail :

helloirsal@gmail.com

\section{Keywords:}

Optimize, Index exposure, Chest PA
Kata kunci:

Optimisasi, Indeks paparan, Dada

Journal of Vocational Health Studies p-ISSN: 2580-7161; e-ISSN: 2580-717x

DOI: 10.20473/jvhs.V4.I2.2020.50-54

Open access under Creative Commons Attribution-Non Commercial-Share A like 4.0 International Licence 


\section{PENDAHULUAN}

Pada saat pandemi COVID-19, pencitraan radiografi menjadi salah satu diagnosa screening pada pasien suspect COVID-19, untuk pasien dewasa dan anak-anak yang kooperatif dapat dilakukan dengan pemeriksaan Posterior Anterior (PA) (Sng et al., 2020) (Woznitza et al., 2020). Pencitraan radiografi dada (CXR) memiliki peran penting dalam membantu diagnosis dan perkembangan perawatan pada pasien COVID-19. CXR menjadi modalitas pencitraan yang paling umum digunakan untuk diagnosa COVID-19 (Cha et al., 2018). Salah satu keuntungan dari CXR adalah peralatan tersedia pada setiap fasilitas kesehatan, dosis radiasi rendah dan kecepatan akuisisi citra. Selain itu, beberapa hasil penelitian merekomendasikan CXR sebagai alat pendukung untuk diagnosa COVID-19 oleh penelitian (Vegar-Zubovic et al., 2020) dan (Tsou et al., 2020). Pemeriksaan CXR pada pasien positif COVID-19 mampu memberikan informasi diagnosa yang sama dengan pemeriksaan CT scan, pemeriksaan CXR pada hari ke 6-11 menunjukan persentase $80 \%$ keberhasilan dalam mendiagnosa dengan sensitivitas sebesar 69\% (Wong et al., 2020).

Radiografer bertanggung jawab dalam menghasilkan kualitas citra yang mana mampu memberikan informasi diagnosa secara akurat dengan mempertimbangkan pemberian dosis radiasi serendah mungkin sesuai prinsip As Low As Reasonably Achievable (ALARA) (Pedersen et al., 2018). Pada kenyataannya, radiografer dalam beberapa kasus sulit menentukan faktor ekposi yang optimal. Hal ini, terkait dengan ukuran ketebalan organ, pengguaan peralatan pencitraan dan pengalaman sebagai praktisi dibidang radiografi (Irsal, 2020). Pemberian faktor eksposi mempengaruhi kualitas citra. Salah satunya yaitu noise, hal ini dapat didefinisikan sebagai intensitas radiasi yang diterima oleh image receptore. Efek citra noise dapat mengurangi batas tegas antara organ yang satu dengan organ yang lainnya (Bond, 1999).

Tugas fisikawan medik adalah mengontrol pemberian dosis radiasi serta menjaga kualitas citra radiografi (Uffmann and Schaefer- Prokop, 2009). Dibutuhkan peran serta antara radiografer dan fisikawan medik dalam melakukan upaya optimasi untuk mengendalikan pemilihan faktor eksposi sesuai dengan klinis pemeriksaan radiografi yang dibutuhkan (Sandborg et al., 2006) dan (Roch et al., 2018). Pada sistem pencitraan $C R$ indikator yang menunjukan respon imaging plate terhadap paparan radiasi disebut Exposure Index (El), El sebanding dengan paparan radiasi yang diberikan oleh pemilihan faktor ekposi. Oleh karena itu, El dapat digunakan sebagai panduan dalam melakukan upaya optimasi yang berhubungan dengan kualitas citra dan dosis radiasi (Dalah, 2020), (Seeram et al., 2013), (Jamil et al., 2018). Selain itu, El dapat menilai penerimaan overexposure, optimal, underexposure (Hinojos-Armendáriz et al., 2018), sehingga penelitian ini bertujuan dapat memberikan informasi exposure index yang optimal sebagai upaya optimisasi pada pemeriksaan chest PA dengan tetap menjaga kualitas citra dan memberikan dosis radiasi serendah mungkin.

\section{MATERIAL DAN METODE}

Penelitian menggunakan data sekunder pemeriksaan radiografi Chest Posterior Anterior di Rumah Sakit Darurat Penanganan COVID-19 Wisma Atlet Jakarta. Penelitian ini bersifat deskriptif kuantitatif dengan melakukan analisa persentase hasil exposure index yang digunakan pada pemeriksaan radiografi chest PA sebagai upaya optimisasi: kualitas citra dan indikator dosis radiasi pada pemeriksaan chest PA. Hal ini dilakukan agar radiografer dapat mengoptimalkan pengetahuan terhadap exposure index sehingga mampu memberikan kualitas citra sebagai penegakan diagnosan dengan tetap mempertimbangkan pemberian dosis radiasi serendah mungkin.

\section{HASIL}

Penelitian ini dilakukan pada tanggal 1-30 Juni 2020 dengan jumlah data 1701 pasien pemeriksaan chest PA di Instalasi Radiologi RSD Penanganan COVID-19 Wisma Atlet Kemoyoran Jakarta, data yang diambil berdasarkan expsoure index yang dihasil oleh radiografer pada saat melakukan pemeriksaan radiografi chest PA pada pasien suspect COVID-19 dan tidak ada intervensi. Standar operasional prosedur pemeriksaan chest PA ditampilkan pada Tabel 1.

Pada Gambar 1, menunjukan persentase penggunaan exposure index yang dihasilkan dari pemeriksaan radiografi chest PA sebagai indikator estimasi dosis radiasi yang diterima pasien, dari jumlah pasien 1071 didapatkan hasil persentase optimization of exposure sebesar 68\%, underexposure 25\%, underexposure (noise) 4\%, overexposure $2 \%$, overexposure (noise) 1\%. Dari hasil ini, menunjukan bahwa radiografer telah melakukan upaya optimisasi terhadap pasien dengan dengan pemilihan parameter faktor eksposi dengan tepat, hal ini dapat dibuktikan dengan jumlah persentase optimization of exposure yang lebih besar dibandingkan underexposure maupun overexposure.

Pada Tabel 2, menunjukan nilai rentang EI berdasarkan informasi CR, peralatan yang digunakan di Instalasi Radiologi menggunakan Agfa CR-15X, dimana sistem $C R$ ini memiliki indikator deviation index dengan pemberikan tanda bar pada monitor dengan warna hijau, kuning dan merah seperti ditunjukan pada Gambar 2, berdasarkan analisa subjektif yang dilakukan maka dibagi menjadi rentang exposure index berdasarkan tanda bar dan kategori exposure yaitu underexposed (noise), underexposed, optimal, overexposed dan overexposed (noise). 
Tabel 1. Standar operasional prosedur pemeriksaan chest PA

\begin{tabular}{ll}
\hline Posisi pasien & $:$ Erect/supine \\
$\mathrm{FFD}$ & $: 150 \mathrm{~cm}$ \\
$\mathrm{CP}$ & $:$ Pada pertengahan di antara kedua angulus scapula \\
$\mathrm{kV}$ & $: 60-80$ \\
\hline & 1.Tampak batas atas apeks paru \\
& 2.Tampak batas bawa tulang vertebrae thorakalis ke 12 \\
Kriteria citra & 3.Tampak batas lateral sinus costophrenicus kiri dan kanan \\
& 4. Tampak jantung dan paru-paru berada pada area/ pertengahan citra radiografi \\
\hline & 1. Pemberian marker R/L \\
& 2. Manipulasi kontras citra radiografi \\
Post-processing & 3. Cropping citra \\
& 4. Zooming citra
\end{tabular}

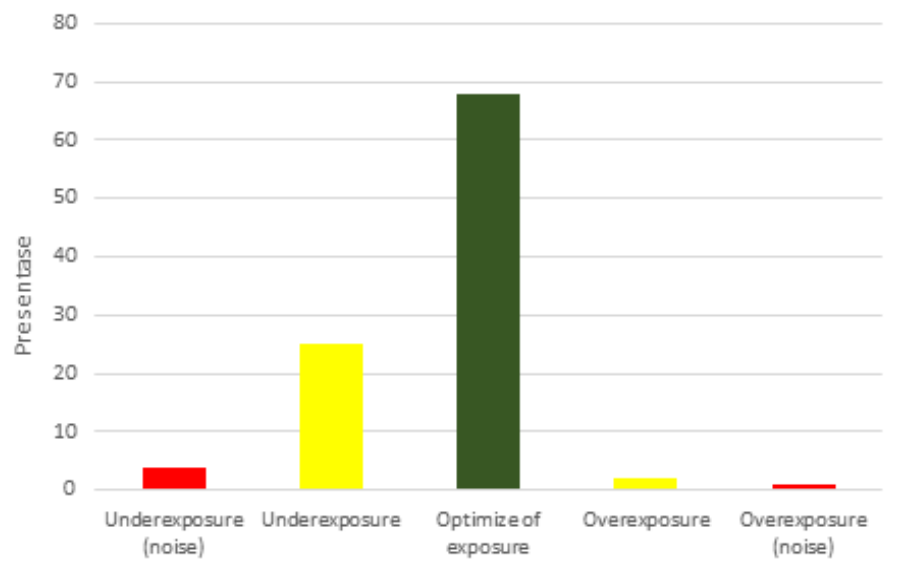

Gambar 1. Persentase penggunaan expsoure index pada pemeriksaan chest PA

Tabel 2. Rentang exposure berdasarkan analisa subjektif dan tanda bar

\begin{tabular}{|c|c|c|}
\hline Rentang El & Kategori & Keterangan \\
\hline $10-30$ & Underexposed (noise) & $\begin{array}{l}\text { Repeat : pengulangan eksposi akibat radiografi men- } \\
\text { galami peningkatan noise, kriteria klinis anatomi tidak } \\
\text { tampak }\end{array}$ \\
\hline $31-60$ & Underexposed & Accepted: menggunakan post processing/windowing \\
\hline $61-238$ & Optimal & Accepted \\
\hline $250-371$ & $\begin{array}{l}\text { Overexposed: dosis radiasi } 2 x \text { dari dosis } \\
\text { rata-rata }\end{array}$ & Accepted : menggunakan post processing/windowing \\
\hline $530-875$ & $\begin{array}{l}\text { Overexposed (noise) : dosis radiasi } 4 x \text { dari } \\
\text { dosis rata-rata }\end{array}$ & $\begin{array}{l}\text { Repeat : pengulangan eksposi akibat radiografi men- } \\
\text { galami peningkatan noise, kriteria klinis anatomi tidak } \\
\text { tampak }\end{array}$ \\
\hline
\end{tabular}

Untuk hasil analisa subjektif nilai underexposed dan overexposed untuk upaya optimasi citra dapat diterima dengan memanfaatkan sistem post processing/ windowing pada saat citra telah selesai diakuisisi, teknik yang digunakan untuk setiap radiografer yang menjadi SOP dalam melaksanakan pemeriksaan radiografi yaitu croping, manipulasi kontras, dan zooming.

Dari hasil yang ditunjukan pada Tabel 2, didapatkan untuk El optimal dibutuhkan nilai El 61-238, kemudian untuk El underexposed nilai El 30-60 dengan kemungkinan pada saat post processing citra di monitor CR harus maksimal, sedang untuk nilai El 10-30 citra yang dihasilkan dapat dipastikan akan mengalami peningkatan noise dan dilakukan repeat. Untuk EI overexposed nilai El 250-371 dan sebaiknya pada saat post processing citra lebih dimaksimalkan agar citra dapat diterima sesuai dengan kualitas citra dan klinis anatomi yang ingin di diagnosa, sedangkan untuk El 530-875 citra akan mengalami peningkatan noise dan dilakukan repeat. 


\section{PEMBAHASAN}

Dari hasil ini, juga dapat memberikan informasi bahwa radiografer telah mengupayakan optimisasi: kualitas citra dan dosis radiasi citra dengan pemilihan faktor eksposi yang disesuaikan dengan kondisi pasien dan memaksimalkan post processing untuk meningkat kualitas citra. Oleh karena, dengan penggunaan komputer radiografi maka citra mampu dioptimisasikan dan dapat menurunkan kejadian pengulangan pemeriksaan chest PA. Dalam kondisi pandemi COVID-19, semua pasien pemeriksaan chest PA merupakan suspected COVID-19 sehingga dengan tidak melakukan pengulangan pemeriksaan maka chest PA menurunkan resiko kontak dan resiko terinfeksi pasien COVID-19. Sehingga, dapat dibuat sebuah skenario optimisasi pada pemeriksaan chest PA seperti pada Gambar 2.

Skenario ini dilakukan berdasarkan pengalaman di rumah sakit dalam kondisi pandemi COVID-19, skenario ini dapat berubah mengikuti kesiapan peralatan di Instalasi Radiologi. Dengan skenario ini, diharapkan radiografer dapat melakukan upaya optimasi pemeriksaan chest PA walaupun data dosis radiasi spesifik menggunakan output radiation tidak tersedia, hal ini perlu disadari bahwa keselamatan dan proteksi radiasi kepada pasien sangat penting dalam melakukan pemeriksaan chest PA. Exposure index dapat digunakan sebagai indikator dosis radiasi dan kualitas citra radiografi. Perlu dipahami, bahwa exposure index tidak memberikan dosis radiasi spesifik, akan tetapi menurut peneltian (Seeram et al., 2013) bahwa exposure index hanya sebagai panduan pemilihan faktor eksposi optimal dengan memberikan informasi dosis dan kualitas citra. Pemeriksaan chest
PA dalam kondisi pandemi COVID-19 digunakan sebagai diagnosa screening COVID-19 dan evaluasi dalam proses pengobatan COVID-19. Oleh karena itu, radiografer diharapkan dengan hasil exposure index dalam melakukan pemilihan faktor esposi yang optimal.

Dalam penggunaan $C R$, perlu diperhatikan beberapa faktor yang mempengaruhi yang salah satunya penggunaan filter pesawat sinar-X berdasarkan penelitian oleh bahwa dengan peningkatan nilai filter diikuti dengan kenaikan nilai El (Ekpo et al., 2014). Penggunaan nilai mAs dapat disesuaikan dengan ukuran tubuh pasien dimana apabila terjadi peningkatan $1 \mathrm{~cm}$ tubuh pasien maka dikompensasi dengan penambahan 15\% nilai mAs (Zheng, 2017), disarankan bahwa pada pasien dengan ketebalan tubuh standar sebaiknya menggunakan teknik kV standar dengan dengan menyeimbangkan dosis radiasi yang diterima dan kualitas citra yang dihasilkan, kemudian untuk pasien dengan ketebalan tubuh lebih besar, maka dapat menggunakan teknik kV tinggi dengan tetap mengutamakan upaya optimisasi agar tercapai konsep ALARA (Metaxas et al., 2019). Selain itu, pengalaman klinisi radiografer menjadi penentuan pemilihan faktor eksposi dan analisa kualitas citra yang dihasilkan, dimana radiografer dapat mengupayakan optimasi citra dengan pertimbangan pemilihan faktor eksposi untuk El yang optimal dari ukuran tubuh, peralatan CR dan pesawat sinar-X yang digunakan.

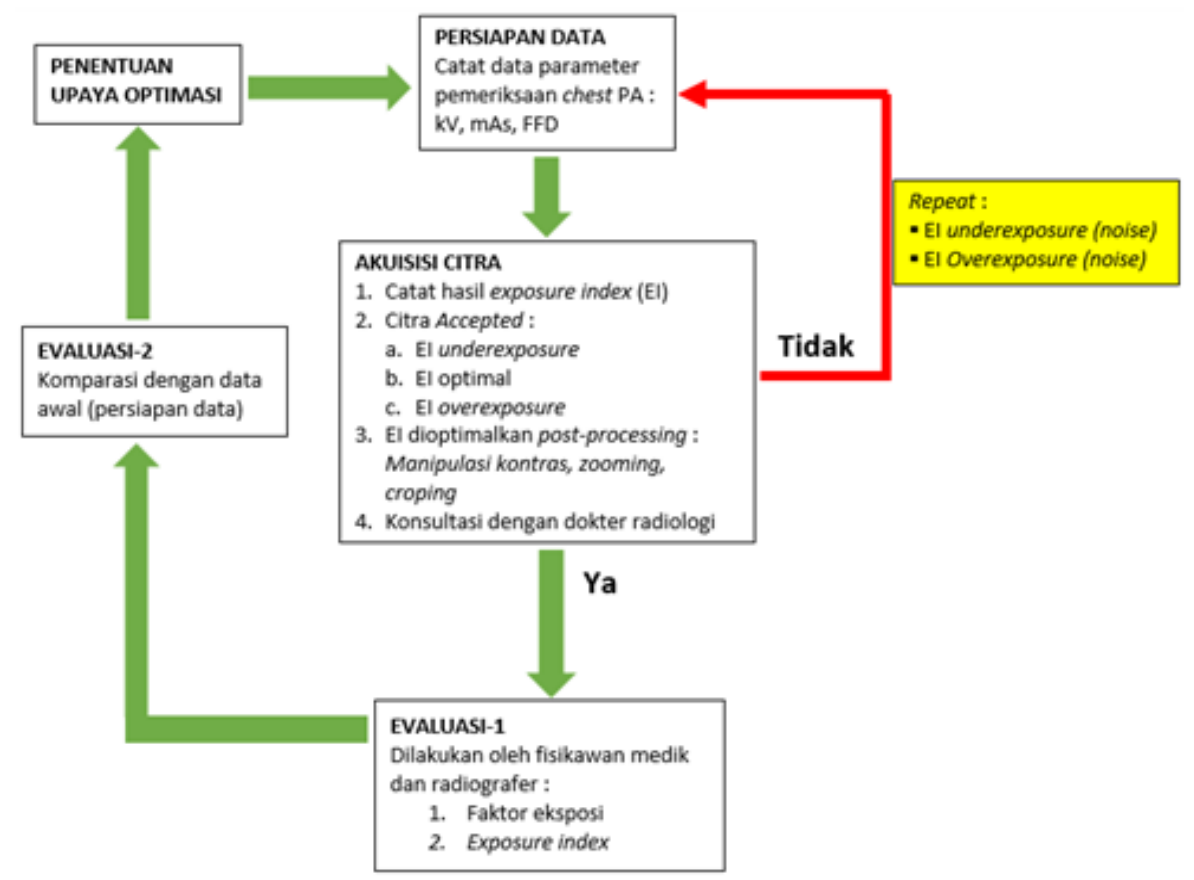

Gambar 2. Skenario upaya optimasi pemeriksaan chest PA 


\section{KESIMPULAN}

Hasil persentase optimization of exposure sebesar $68 \%$, underexposure 25\%, underexposure (noise) 4\%, overexposure $2 \%$, overexposure (noise) $1 \%$. Radiografer telah mengupayakan optimisasi: kualitas citra dan dosis radiasi citra dengan pemilihan faktor eksposi yang disesuaikan dengan kondisi pasien dan memaksimalkan post processing untuk meningkat kualitas. Dalam melakukan upaya optimisasi pada sistem pencitraan CR perlu pemahaman tentang El. Hal ini berkaitan tentang kategori underexposed, optimal dan overexposed, selain itu radiografer dapat memanfaatkan post processing/ windowing untuk meningkatkan kualitas citra.

\section{UCAPAN TERIMA KASIH}

Peneliti mengucapkan terima kasih kepada semua radiografer RS Darurat Wisma Atlet Jakarta dan pihak yang telah berkontribusi terhadap penelitian ini. Penulis menyatakan tidak ada konflik kepentingan dengan pihak yang terkait dalam penelitian ini.

\section{DAFTAR PUSTAKA}

Bond, N., 1999. Optimization of Image Quality and Patient Exposure in Chest Radiography. Radiography 5, 29-31.

Cha, M.J., Chung, M.J., Kim, K., Lee, K.S., Kim, T.J., Kim, T.S., 2018. Clinical Implication of Radiographic Scores in Acute Middle East Respiratory Syndrome Coronavirus Pneumonia: Report from a Single Tertiary-Referral Center of South Korea. Eur. J. Radiol. 107, 196-202.

Dalah, E.Z., 2020. Quantifying Dose-Creep for Skull and Chest Radiography using Dose Area Product and Entrance Surface Dose: Phantom Study. Radiat. Phys. Chem. 167, 108-231.

Ekpo, E.U., Hoban, A.C., McEntee, M.F., 2014. Optimisation of direct digital chest radiography using $\mathrm{Cu}$ filtration. Radiography 20, 346-350.

Hinojos-Armendáriz, V.I., Mejía-Rosales, S.J., Franco-Cabrera, M.C., 2018. Paediatric radiology Optimisation Chest radiography Radiation protection Neonatal radiography. Radiography 24, 104-109. Irsal, M., 2020. Evaluasi Faktor Eksposi dalam Upaya Optimisasi pada Pemeriksaan Radiografi Chest PA Suspected COVID - 19. In: Adnin, R. (Ed.), KOCENIN Serial Konferensi. Kocenin, Jakarta, pp. 1-10. Jamil, A., Mohd, M.I., Zain, N.M., 2018. The Consistency of Exposure Indicator Values in Digital Radiography Systems. Radiat. Prot. Dosimetry 182, 413-418.

Metaxas, V.I., Messaris, G.A., Lekatou, A.N.., Petsas, Theodore G. Panayiotakis, G.S., 2019. Patient Dose in Digital Radiography Utilising BMI Classification. Radiat. Prot. Dosimetry 184, 155-167.
Pedersen, C.C.E., Hardy, M., Blankholm, A.D., 2018. An Evaluation of Image Acquisition Techniques, Radiographic Practice and Technical Quality in Neonatal Chest Radiography. Med. Imaging Radiat. Sci. 49, 257-264.

Roch, P., Célier, D., Dessaud, C., Etard, C., 2018. Using Diagnostic Reference Levels to Evaluate The Improvement of Patient Dose Optimisation and The Influence of Recent Technologies in Radiography and Computed Tomography. Eur. J. Radiol. 98, 68-74.

Sandborg, M., Tingberg, A., Ullman, G., Dance, D.R., Carlsson, G.A., 2006. Comparison Of Clinical and Physical Measures of Image Quality in Chest and Pelvis Computed Radiography at Different Tube Voltages. Med. Phys. 33.

Seeram, E., Davidson, R., Bushong, S., Swan, H., 2013. Radiation Dose Optimization Research: Exposure Technique Approaches in CR Imaging - A Literature Review. Radiography 19, 331-338.

Sng, L.H., Arlany.L., Toh, L.C., Loo, T.Y., Ilzam, N.S., Wong, B.S.S., Lanca, L., 2020. Initial Data from An Experiment to Implement A Safe Procedure to Perform PA Erect Chest Radiographs for COVID-19 Patients with A Mobile Radiographic System in A "Clean" Zone of The Hospital Ward. Radiography $1-6$.

Tsou, I.Y.Y., Liew, C.J.Y., Tan, B.P., Chou, H., Wong, S.B.S., Loke, K.S.H., Quah, R.C.W., Tan, A.G.S., Tay, K.H., 2020. Planning and Coordination of The Radiological Response to The Coronavirus Disease 2019 (COVID-19) Pandemic: The Singapore Experience. Clin. Radiol. 1-10.

Uffmann, M., Schaefer- Prokop, C., 2009. Digital Radiography: The Balance between Image Quality and Required Radiation Dose. Eur. J. Radiol. 72, 202-208.

Vegar-Zubovic, S., Izetbegovic, S., Zukic, F., Jusufbegovic, S., Kristic, S., Prevljak, S., Sehic, A., Julardzija, F., 2020. A Case Series of Chest Imaging Manifestation of COVID-19. Radiography 26, e319-e321.

Wong, H.Y.F., Lam, H.Y.S., Fong, A.H.-T., Leung, S.T., Chin, T.W.-Y., Lo, C.S.Y., Lui, M.M.-S., Lee, J.C.Y., Chiu, K.W.-H., Chung, T.W.-H., Lee, E.Y.P., Wan, E.Y.F., Hung, I.F.N., Lam, T.P.W., Kuo, M.D., Ng, M.-Y., 2020. Frequency and Distribution of Chest Radiographic Findings in Patients Positive for COVID-19. Radiology 296, 72-78.

Woznitza, N., Nair, A., Hare, S.S., 2020. COVID-19: A Case Series to Support Radiographer Preliminary Clinical Evaluation. Radiography 26, e186-e188.

Zheng, X., 2017. Patient Size Based Guiding Equations for Automatic mAs and kVp Selections In General Medical X-Ray Projection Radiography. Radiat. Prot. Dosimetry 174, 545-550. 